\title{
La medición de la calidad de los Servicios Socioculturales en la Administración local: el caso de Alcobendas
}

\section{José Luis Palacios, Francisco José Fulgueiras y Celia Catalina *}

\section{Los Servicios Socioculturales}

y la modernización de la Administración local: el sistema de calidad del Ayuntamiento de Alcobendas

La llegada de la democracia a nuestro país comportó un notabilísimo fortalecimiento de las Administraciones locales. Los ayuntamientos, aunque poseían una honda raigambre en nuestra cultura, habian ido quedando paulatinamente arrinconados en el sistema general de la Administración por falta de reales posibilidades de actuación, como consecuencia de las limitaciones jurídicas y políticas y de su endémica penuria económica. La Constitución de 1978 y la posterior Ley Reguladora de las Bases del Régimen Local de 1985 les confirieron un nuevo status legal y una capacidad económica y financiera que les permitieron adquirir un relieve institucional y una presencia en la vida pública sin precedentes. Fruto de esta circunstancia, la generalidad de los ayuntamientos acometió la tarea de mejorar los servicios públicos clásicos y poner en marcha algunos nuevos. Entre estos últimos figuraban unos servicios de nuevo cuño que hoy se encuentran prácticamente estandarizados en la mayoría de los municipios y que reciben la denominación genérica de Servicios Socioculturales, rótulo bajo el que se articulan una serie de servicios a las personas en las áreas de juventud, tercera edad, cultura y educación, principalmente, que se prestan desde un conjunto de infraestructuras, conocidas como equipamientos socioculturales (casas de cultura, casas de juventud, centros cívicos, hogares de tercera edad, etc.), y que han contribuido a mejorar sustancialmente la vida social y cultural de los ciudadanos españoles.

Algunos ayuntamientos decidieron llevar a cabo la prestación de estos servicios merced a un proceso de descentralización que se plasmó en la creación de organismos autónomos, fundaciones y patronatos, en la idea de que para dar este tipo de servicios la mejor fórmula es una estructura administrativa y funcional que proporcione rapidez y agilidad, sin las trabas burocráticas que tan frecuentemente se dan en el marco de la Administración clásica.

En el Ayuntamiento de Alcobendas ${ }^{1}$ fue ésta la forma de actuar y en 1982 se creó, al amparo del Reglamento de Servicios de las Corporaciones Locales de 1955 (arts. 85-88), el Patronato Sociocultural, organismo comercial autónomo que, después de algunas importantes transformaciones, acoge los Servicios Socioculturales propiamente dichos que hoy presta este organismo municipal: Casa de la Cultura, Casa de la Juventud, Casa de la Mujer, Casa de las Asociaciones-Centros Cívicos, Escuela de Música, Teatro Auditorio Municipal, Medios Audiovisuales, 
Bibliotecas Municipales, Centro de Formación e Inserción Laboral, Universidad Popular, Escuelas Infantiles y Centro Psicopedagógico Municipal. El actual Patronato Sociocultural del. Ayuntamiento de Alcobendas cuenta con una plantilla de unos 260 trabajadores para atender a una población cercana a las 90.000 personas y su presupuesto para el año 2000 fue de 1.873 millones de pesetas.

Ya en 1985, se comenzó en el Patronato Sociocultural la puesta en funcionamiento del Sistema de Programación por Objetivos (SPPO), una forma de gestión para la Administración local que hace propios los principios de management de la celebérrima «Dirección por Objetivos» que las modernas empresas de todos los sectores productivos habían asumido hacía ya tiempo (MC CONKEY, 1972; DruCKER, 1985; Tena, 1991; Drudis, 1992; Díaz, 1992; LongO, 1993). La paulatina implantación del SPPO comenzó precisamente en el Patronato Sociocultural porque la estructura de este organismo y la naturaleza de sus servicios lo hacían más apropiado para probar y desarrollar el sistema. El SPPO comportaba no sólo una manera de planificar las acciones de intervención social, sobre la base de la información de la demanda, sino también un sistema de presupuestación por objetivos y un mecanismo regulador de control de la gestión. Además de los indicadores internos de logro de objetivos generales y específicos de cada programa de intervención, el SPPO favoreció la implantación de un conjunto de indicadores de satisfacción de usuarios de los servicios, dentro de la filosofía de lo que en las empresas de servicios se denomina «gestión orientada al cliente» (FLIPO, 1989; SHAW, 1991; CHIAS, 1991; Brown, 1992), piedra angular de la política de calidad sobre la que el Ayuntamiento ha desarrollado su proceso de modernización administrativa. La modernización en la Administración local alcobendina, por tanto, no comporta simplemente acometer un proceso de transformación de los procedimientos de trabajo y de coordinación interdepartamental, sino también implementar un sistema de información para el control de la gestión que tiene en la medición de las actitudes y opiniones de los ciudadanos sobre los servicios recibidos uno de sus vectores axiales.

En los últimos años, sin embargo, con la creación del Departamento de Calidad y del Comité Impulsor de la Calidad (interdepartamental) y su adscripción al Club Gestión de Calidad (élite de la Asociación Española para la Calidad), el Ayuntamiento ha adoptado una filosofía de gestión más depurada y ha tomado como referente teórico el modelo de autoevaluación

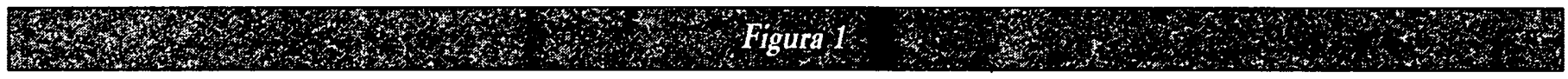

\section{MODELO EUROPEO PARA LA GESTIÓN DE LA CALIDAD EFQM}

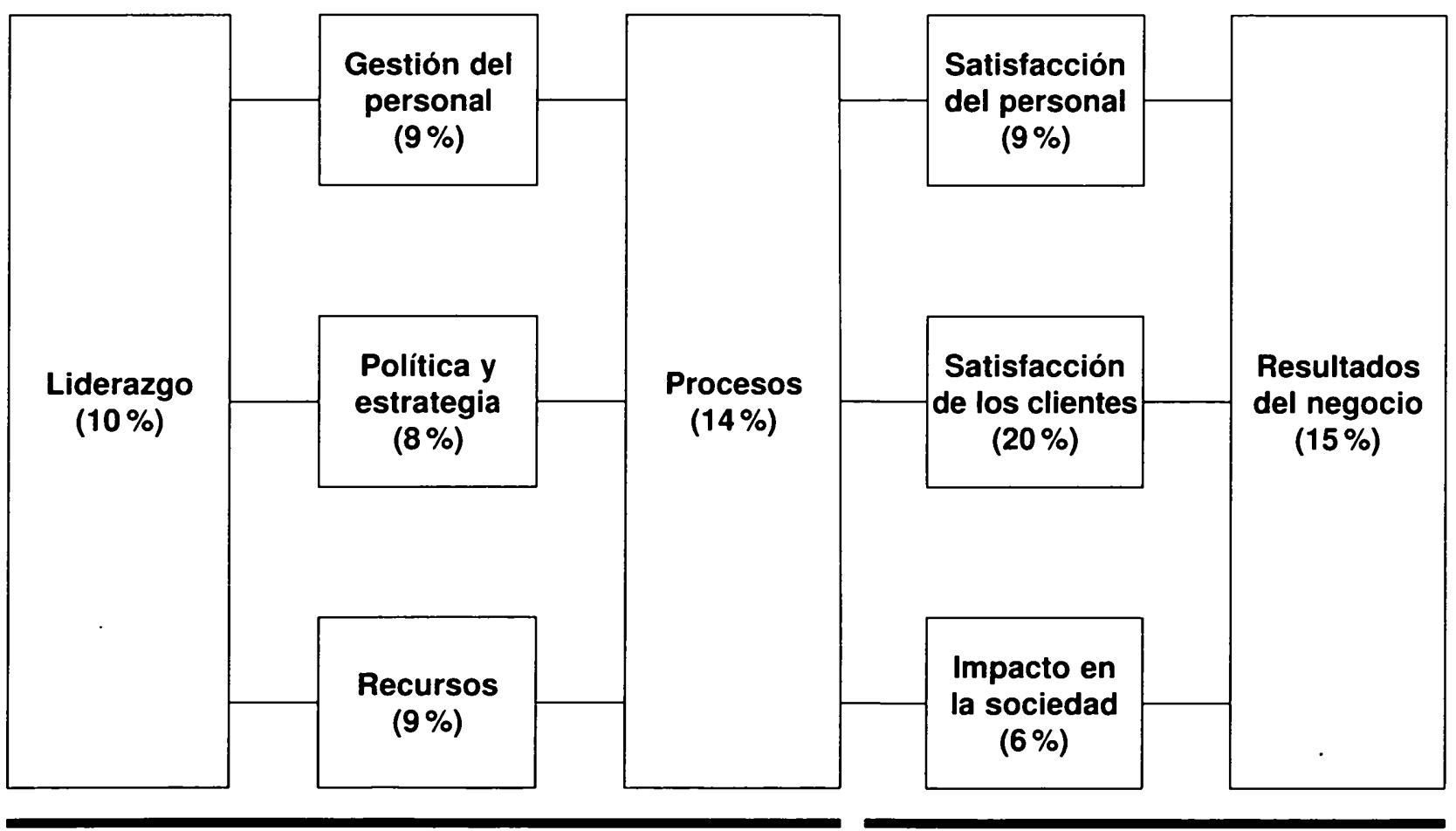


de la calidad EFQM (European Foundation for Quality Management), que se ha considerado más oportuno para evaluar los servicios municipales que otros modelos al uso como, por ejemplo, la ISO 9000 para empresas de servicios. El modelo EFQM establece dos parámetros fundamentales en la consecuciónmedición de la calidad en una organización: Agentes (50\%) y Resultados (50\%), asignando porcentajes de importancia a una serie de factores como son el liderazgo, los recursos, los procesos, la satisfacción de los clientes o el impacto en la sociedad, ocupando un lugar predominante la satisfacción de los clientes, con un $20 \%$ sobre el total (Figura 1).

\section{La investigación social - en el Sistema de Calidad del Ayuntamiento de Alcobendas}

En consonancia con lo expresado más arriba, podemos afirmar que gran parte del éxito del Sistema de Calidad del Ayuntamiento de Alcobendas depende, por un lado, de la adecuada y continua identificación de las demandas que expresan los ciudadanos en virtud de sus problemas y necesidades y, por otro, de la sistemática detección del nivel de satisfacción que éstos tienen con la ciudad en la que habitan y, más concretamente, con cada uno de los equipamientos y servicios que dependen del Ayuntamiento. Otro vector fundamental de este proceso es el análisis de las expectativas, porque la satisfacción está también unida a la percepción que el ciudadano tiene de cómo se presta el servicio y a la expectativa que tenía respecto del mismo (servicio esperado). Es precisamente en relación con estos aspectos de la gestión del Sistema de Calidad donde cobra una importancia especial la investigación social y donde surge la necesidad de contar con un servicio de estudios como es el Departamento de Investigación Social y Evaluación de Politicas Municipales, departamento que lleva a cabo la mayor parte de los estudios e investigaciones sociales que precisa el Ayuntamiento o cualquiera de sus Patronatos para conocer la realidad social alcobendina, sin perjuicio de que los trabajos de campo de algunas prospecciones se contraten con empresas de investigación de mercados y opinión pública cuando las circunstancias así lo aconsejan. Sus diseños de investigación comprenden tanto estudios cuantitativos (explotación de datos secundarios, encuestas) como cualitativos (grupos de discusión, series de entrevistas), en función de los requerimientos informativos y de las características del asunto investigado. Frecuentemente, se opta por la combinación de ambas aproximaciones, cuan- titativa y cualitativa, como procedimiento para aumentar la potencia de la prospección y como fórmula de triangulación para garantizar en mayor grado la validez externa de la misma. Es el caso de los estudios de calidad de los servicios socioculturales municipales, en los que se realizan un cualitativo ad boc y una encuesta estandarizada para esta clase de medición: la articulación de técnicas cuantitativas y cualitativas proporciona mayor riqueza informativa y robustece la validez del diseño de investigación, pues los cualitativos ofrecen matices opináticos y actitudinales en un terreno donde resultan especialmente convenientes y, al tiempo, ya que estudian similares ejes valorativos en los usuarios de los servicios, permiten un contraste de sus resultados con los de las encuestas que mejora la confiabilidad de la información obtenida.

Uno de los cometidos de la Dirección de Investigación y Evaluación del Ayuntamiento de Alcobendas es el de desarrollar toda esa vertiente del Sistema de Calidad a la que hemos hecho referencia, es decir, identificar las necesidades y demandas ciudadanas, evaluar las expectativas (respecto a los servicios y respecto al futuro de la ciudad), analizar el grado de satisfacción de los usuarios y, finalmente, establecer los niveles de calidad que se obtienen en los diferentes servicios municipales y en la gestión global de la ciudad. Para llevar a cabo esta labor, son varios los tipos de estudios que periódicamente se realizan:

- Informe anual de las reclamaciones y sugerencias de los ciudadanos.

- Estudios monográficos de área para abordar proyectos de mejora.

- Encuestas de satisfacción y calidad de la ciudad.

- Estudios de calidad de los servicios y equipamientos municipales.

El análisis de reclamaciones y sugerencias de los ciudadanos permite conocer aquellos aspectos de los servicios municipales que no están a la altura de lo que el usuario espera. En una primera fase, las reclamaciones que cualquier ciudadano puede tramitar sirven para detectar errores en la prestación de servicios y para establecer cuáles son los puntos débiles del sistema de servicios y equipamientos municipales. A partir de aquí, se pueden introducir modificaciones que conduzcan a su adecuado funcionamiento. De la misma forma, las sugerencias tramitadas son trasladadas a los responsables de cada área con el objeto de introducir mejoras que finalmente reflejen lo que los usuarios proponen, de tal forma que sean éstos los que determinen el nivel de calidad de los servicios.

Una segunda vía de investigación encuadrada en el Sistema de Calidad del Ayuntamiento de Alcobendas es la que representan los estudios monográficos que se llevan a cabo en los procesos de planificación de proyectos de mejora de determinadas áreas de actuación. Las investigaciones de área son utilizadas como base documental y como fuente de información legitimadora de nuevos proyectos o modificaciones de diversos 


\section{AYTO. ALCOBENDAS: EVOLUCIÓN DEL NÚMERO DE RECLAMACIONES Y SUGERENCIAS}

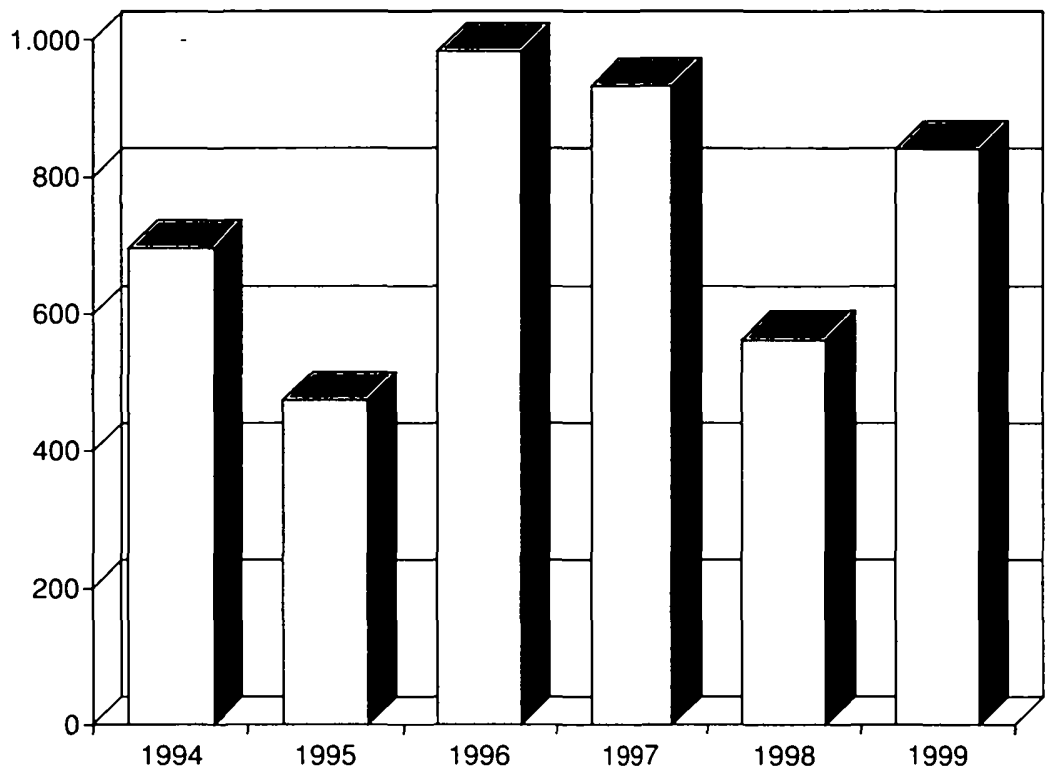

Fuente: Dirección de Investigación Social y Evaluación. Análisis de reclamaciones y sugerencias, 2000.

programas municipales. Esta línea de investigación permite prever el impacto social de programas y políticas locales de cierta envergadura e inversión presupuestaria, además de proporcionar un sólido soporte a la hora de detectar nuevas necesidades y demandas de los ciudadanos. A título de ejemplo, podemos citar algunos de los estudios que se han realizado recientemente dentro de esta línea de investigación: Legitimidad de la obligación fiscal (percepción social de los contribuyentes), Difusión e impacto de los medios de información locales, Actitudes y expectativas de los jóvenes de Alcobendas...

Las encuestas anuales de satisfacción ciudadana y calidad de la ciudad constituyen uno de los ejes informativos principales sobre los que se asienta el Sistema de Calidad del Ayuntamiento de Alcobendas. El objetivo último de estas investigaciones sería tomar el pulso a la ciudad o, lo que es lo mismo, averiguar qué es lo que se espera del Ayuntamiento y cómo se valora lo que de él se recibe. No hay que olvidar que una buena parte del esfuerzo investigador va encaminado a detectar las necesidades y demandas ciudadanas, sin las cuales no podrían elaborarse planes de actuación que se ajusten a la realidad social. Son tres las temáticas principales de estas encuestas: Evolución de la ciudad, Comparativa ciudad ideal/ciudad real y Equipamientos Municipales. Las Figuras 3, 4, 5 y 6 muestran gráficamente los resultados de algunos de estos estudios anuales de satisfacción de los ciudadanos en relación con la calidad de la ciudad.
Finalmente, el Departamento de Investigación y Evaluación realiza investigaciones sobre determinados servicios y equipamientos municipales, entre los que destacan los Estudios de Calidad en los Servicios Socioculturales, claro exponente del programa de evaluación del Sistema de Calidad que ha implantado el Ayuntamiento de Alcobendas, en cuya consideración nos detendremos con cierto detalle en el apartado siguiente.

\section{Los estudios de calidad de los Servicios Socioculturales del Ayuntamiento de Alcobendas:} una propuesta metodológica

Como señalábamos al principio, el Patronato Sociocultural ha sido tradicionalmente, además de una plataforma ágil y flexible para la prestación de servicios a las personas, un campo de pruebas de los modernos sistemas de gestión implantados en el Ayuntamiento de Alcobendas. No es accidental, por tanto, 


\section{Figgera 3}

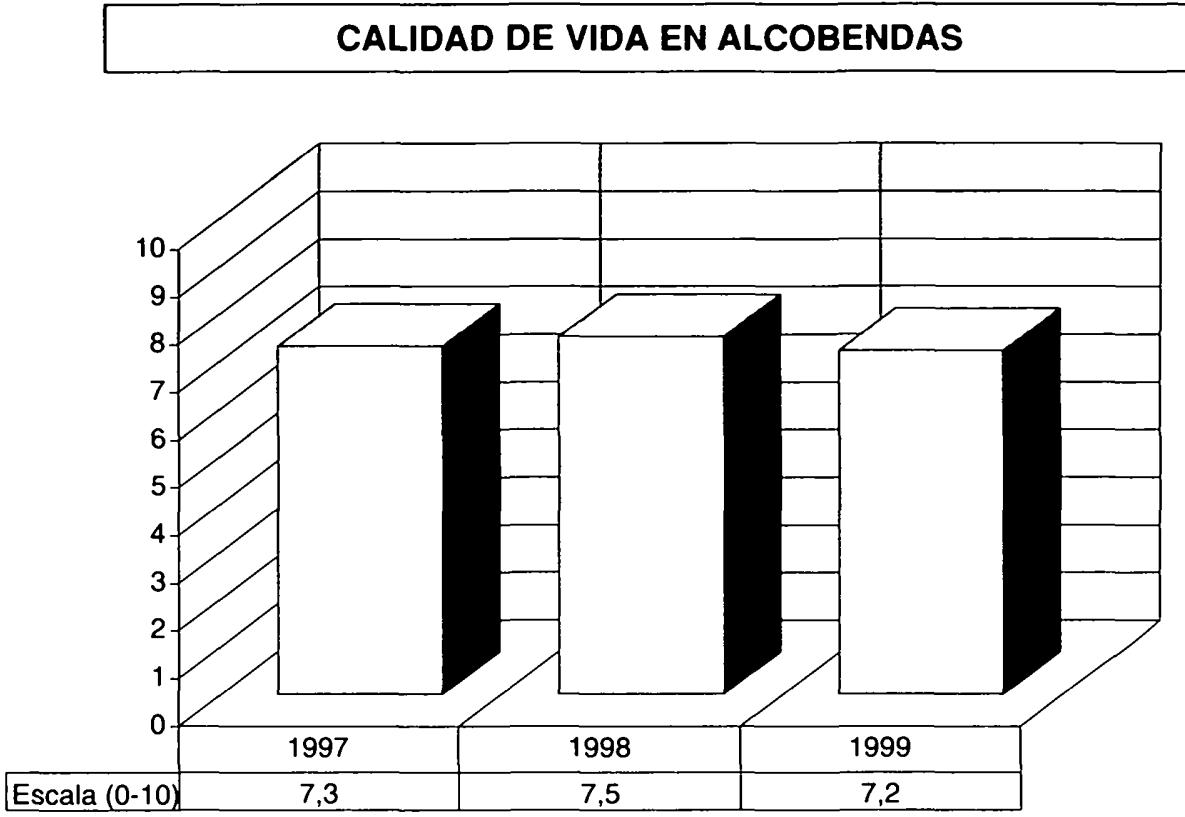

Fuente: Dirección de Invcstigación Social y Evaluación. Encuesta de calidad de la ciudad, 1999.

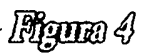

\section{EVOLUCIÓN DE ALCOBENDAS EN LOS ÚLTIMOS AÑOS (\%)}

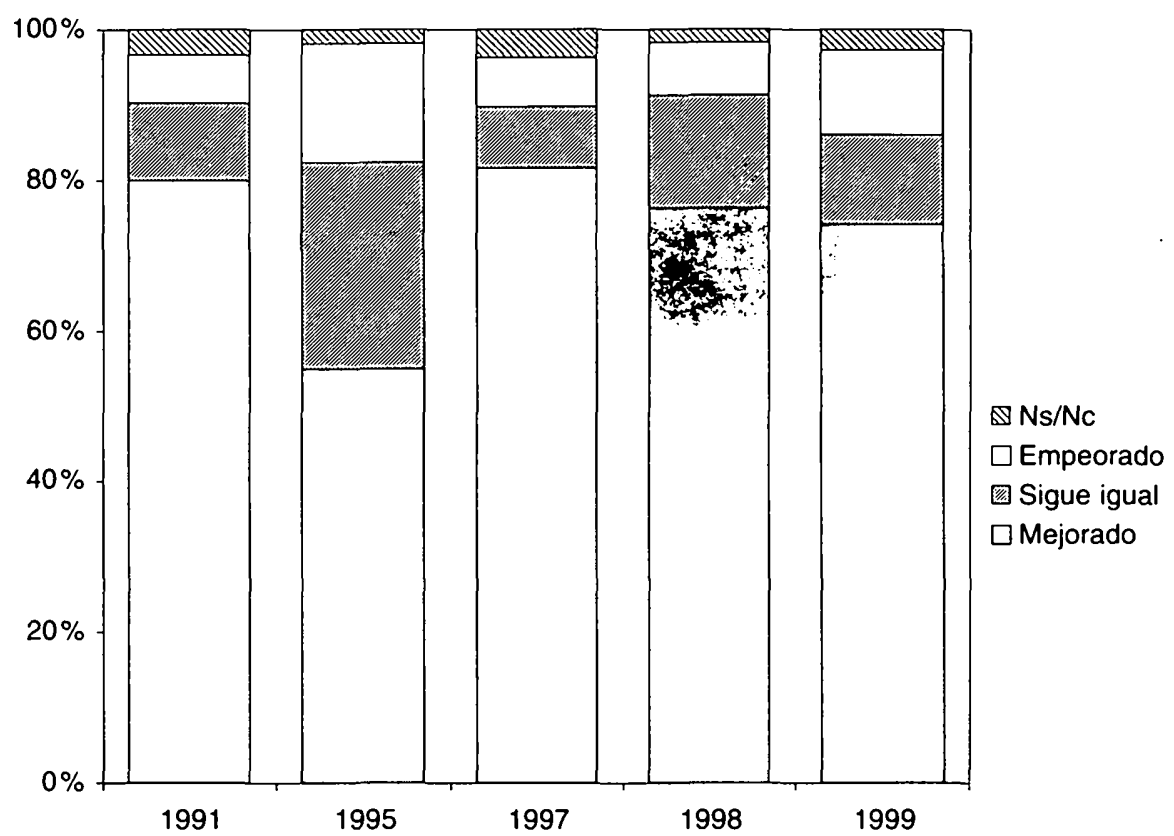

Fuente: Dirección de Investigación Social y Evaluación. Encuesta de calidad de la ciudad, 1999 


\section{Figura 5}

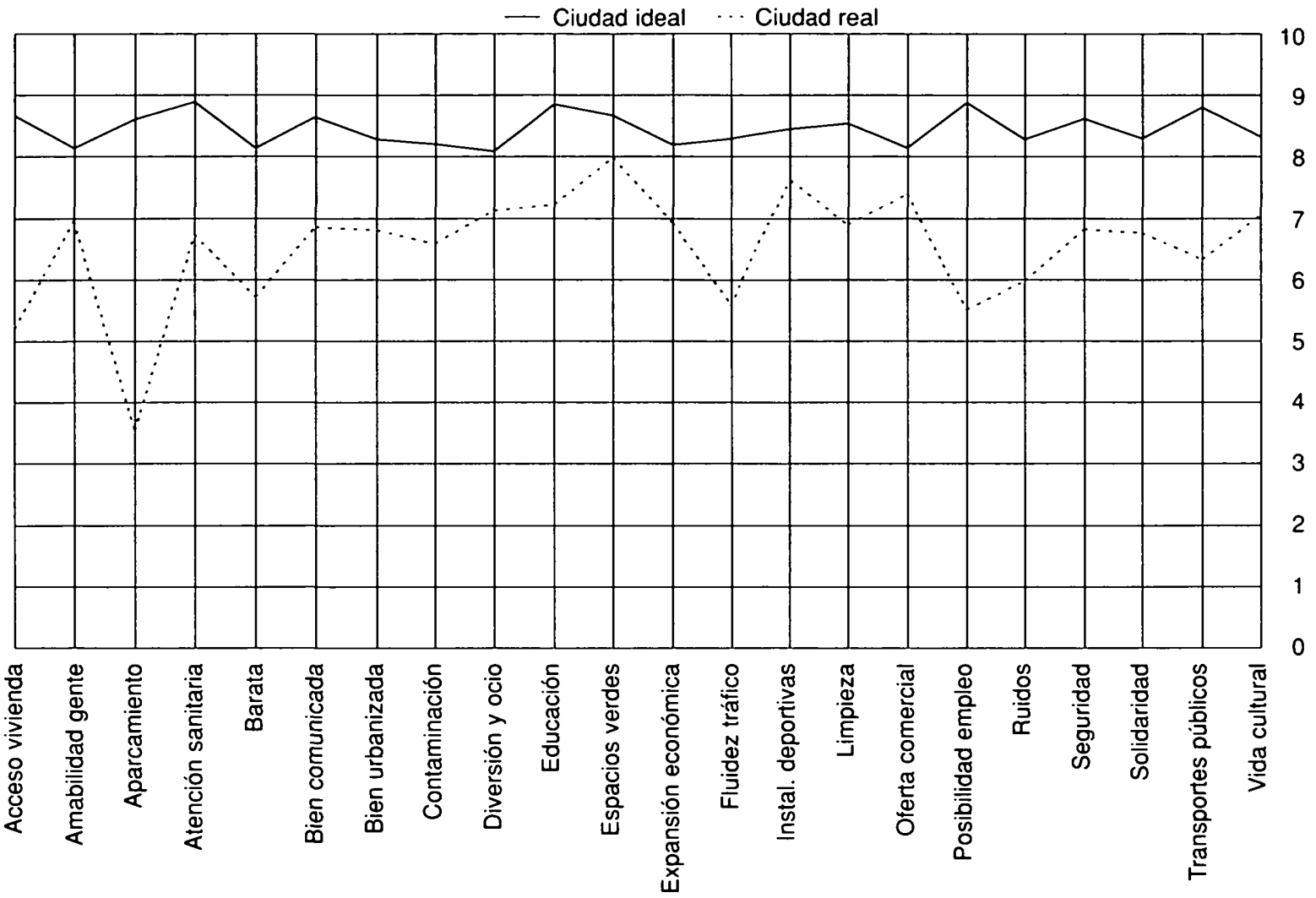

Fuente: Dirección de Investigación Social y Evaluación. Encuesta de calidad de la ciudad, 1999.

que sea en los Servicios Socioculturales encuadrados en este Patronato donde se han implementado los más completos y sofisticados estudios de medición de calidad desde el punto de vista de los usuarios que se llevan a cabo en la Administración local alcobendina.

La primera tarea aquí ha sido dilucidar cuáles son los atributos de calidad en los que el usuario se basará a la hora de evaluar la calidad del servicio que está utilizando. Existen en la bibliografía especializada algunos referentes prácticos sobre las dimensiones de la calidad que se han podido extrapolar y servir de punto de partida en un plan de medida. Probablemente, los autores más citados a este respecto son el grupo formado por ZeITHAML, Parasuraman y BerRy (1993), que en sus investigaciones establecieron los diez «determinantes de la calidad de servicio» (escala SERVQUAL), que vienen a coincidir con las variables objeto de estudio propuestas en la Autoevaluación según el Modelo Europeo de Excelencia Empresarial (EFQM-Criterio 6, subcriterio 6a), marco del actual Sistema de Calidad del Ayuntamiento de Alcobendas. Estos atributos de calidad encontrados por estos autores son, en líneas generales, extrapolables a los servicios públicos en general, aunque, lógicamente, hay que adaptarlos a la variedad de servicios y prestaciones que se ofrecen en las Administraciones públicas. Estos autores sugieren que existen cinco dimensiones de calidad, cuatro intangibles (fiabilidad, capacidad de respuesta, seguridad y empatía) y una muy general de aspectos tangibles. Las dimensiones intangibles son, por tanto, las relativas a la interacción entre empleados y usuarios o a «cómo» se presta el servicio y las dimensiones tangibles se refieren a los aspectos físicos del servicio o a «qué» se ofrece en la prestación del servicio.

La definición resumida de los atributos de calidad incluidos en esas dimensiones señaladas es la siguiente:

a) Dimensiones intangibles:

- Fiabilidad: Prestar los servicios adecuadamente, cumplir lo prometido, y hacerlo sin cometer errores.

- Capacidad de respuesta: Disposición de los empleados para ayudar a los usuarios y prestarles atención, así como hacer las cosas puntualmente y con rapidez.

- Empatia: Cuidado y atención individualizada a los usuarios. El usuario debe percibir que el empleado público local está a su servicio. Comprende los siguientes atributos: 


\section{Figura 6}

\section{VALORACIÓN DE LOS EQUIPAMIENTOS MUNICIPALES (Escala de 0 a 10)}

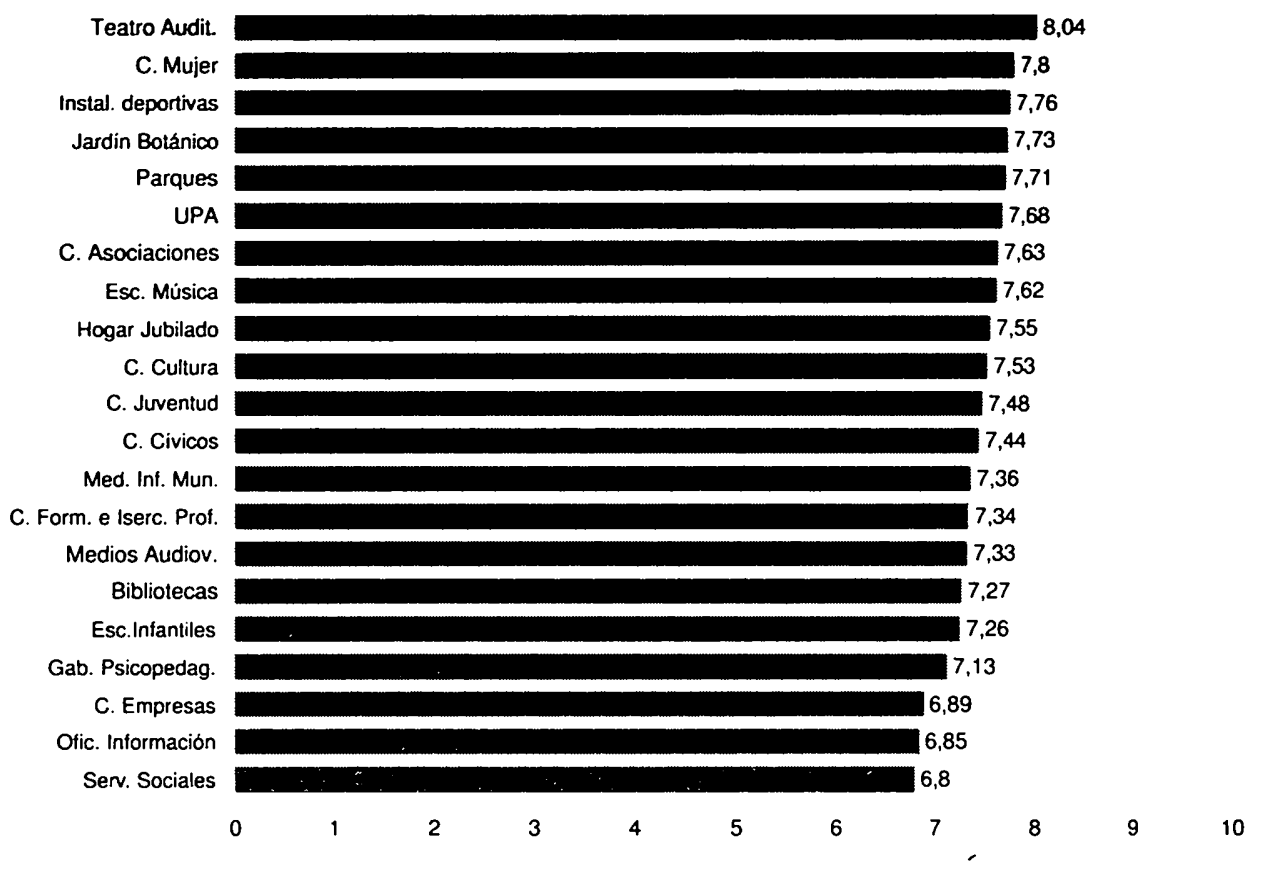

Fuente: Dirección de Investigación Social y Evaluación. Encuesta de calidad de la ciudad, 1999.

- Accesibilidad: Los servicios son fáciles de obtener y localizar, además de cómodos de utilizar.

- Comunicación: Informar a los usuarios con un lenguaje comprensible y saber escucharles.

- Comprensión: Esfuerzo por conocer a los ciudadanos y sus necesidades. El usuario debe percibir que el Ayuntamiento entiende sus problemas.

- Seguridad: Garantizar la seguridad de los ciudadanos en el uso de los servicios, tanto física, como los aspectos relacionados con la confianza que inspiran los empleados a los usuarios. Comprende los siguientes atributos:

- Profesionalidad/Competencia: los trabajadores municipales tienen las destrezas requeridas para poder hacer bien las cosas.

- Cortesía: Tratar a los ciudadanos con amabilidad, consideración, respeto y máxima atención.

- Credibilidad: Los servicios se prestan honestamente, por empleados que están a su servicio. Conocer e interesarse por los problemas de los ciudadanos.

- Seguridad: Garantizar la seguridad de los ciudadanos en el uso de los servicios.

\section{b) Dimensiones tangibles:}

Se refieren al conjunto de atributos de los elementos tangibles, a partir del principio de que el entorno donde se prestan los servicios del Ayuntamiento debe aportar elementos de calidad:

- Instalaciones físicas: estado de conservación y limpieza de los edificios.

- Comodidad y medios disponibles:, sillones, mesas, salas de espera, materiales de comunicación, etc.

- Personal: apariencia, identificación personal.

- Decoración y ambiente: mobiliario, luminosidad, temperatura, ruido, etc.

\subsection{Aproximación metodológica 1: las Encuestas de Satisfacción de Usuarios}

Una vez identificadas y consensuadas las dimensiones de la calidad, y a falta de una proposición metodológica dirigida específicamente a los servicios públicos locales, el Departamento de Investigación y Evaluación ha establecido un sistema propio de medición cuantitativa, consistente en un cuestionario estándar, basado en los criterios de calidad mencionados, válido para todos los servicios públicos del Ayuntamiento. Lógicamente, dada la cantidad y diversidad de servicios, ha sido necesaria la adaptación de esta herramienta a cada uno de ellos. 
Los servicios públicos en los que se mide la satisfacción de los usuarios son todos aquellos en los que hay una relación más directa con el usuario, dependientes del propio Ayuntamiento o de alguno de sus Patronatos (Deportes, Sociocultural y Salud e Integración Social). Anualmente se seleccionan qué servicios se van a estudiar de cada uno de esos organismos autónomos. Hasta el momento se han realizado por primera vez encuestas de satisfacción de usuarios en los siguientes servicios:

- Patronato de Salud e Integración Social: Servicios Sociales.

- Patronato Municipal de Deportes: usuarios de actividades deportivas (sólo natación y gimnasia); usuarios por libre; usuarios pertenecientes a asociaciones y clubes deportivos.

- Patronato Sociocultural: Escuelas Infantiles; Escuela Municipal de Música y Danza; Teatro Auditorio; Bibliotecas Municipales; Departamento de Usuarios; Universidad Popular, Casa de la Mujer y Centro de Formación e Inserción Laboral.

- También se llevan a cabo investigaciones sobre otras cuestiones relacionadas con la calidad dentro del Ayuntamiento, tales como los estudios internos de satisfacción de los trabajadores municipales con determinadas prestaciones contractuales, entre los que puede citarse a título de ejemplo la serie de estudios de calidad del reconocimiento médico a la plantilla de personal.

En la elaboración del cuestionario estándar de satisfacción de usuarios, ha sido necesario seguir una serie de requerimientos, unos propios de toda investigación que se pretenda hacer con la máxima rigurosidad y otros exigidos por la demanda de utilidad de la Corporación. Las cuestiones que en este sentido se han considerado más importantes son las siguientes:

- Validez y fiabilidad: se diseña un cuestionario en el que se incluyen los parámetros de calidad comúnmente aceptados (escala SERVQUAL, ya testada por sus autores). Debe aportar información sobre la calidad de los servicios prestados por la Institución a todos los niveles. Calidad en la estructura (recursos humanos, físicos, financieros), en el proceso (datos que describen las actividades y tareas de los profesionales implicados en los servicios públicos) y en los resultados (satisfacción de los usuarios). Las muestras tienen los tamaños teóricos precisos para garantizar la representatividad. Las escalas están estandarizadas según los usos comunes en investigación social (el gradiente $0-10$ se estima especialmente apropiado para recoger valoraciones de usuarios comunes).

- Adaptabilidad: el modelo de cuestionario se tiene que adaptar a todos los servicios municipales, respetando las singularidades de cada uno de ellos.

- Participación: la forma de medir la «satisfacción de los usuarios» a través del cuestionario estándar debe ser aceptado por todos y cada uno de los responsables de los servicios municipales que se van a ver implicados en el proceso.
- Orientación al usuario: los profesionales y los técnicos municipales son los responsables de diseñar los servicios que la Corporación tiene que prestar y de cómo hacerlo, pero en ningún caso son quienes han de determinar su calidad, esto les corresponde a los ciudadanos.

- Longitudinalidad: tiene que haber una continuidad en la evaluación. La medición de la satisfacción del usuario en cada uno de los servicios se realizará cada cuatro años. Mediante medidas longitudinales de la satisfacción, se puede observar si los esfuerzos dedicados a la mejora de la calidad se traducen en un aumento de la satisfacción.

- Pragmatismo: las encuestas responden a una finalidad práctica, sirven para corregir defectos y, por tanto, nos alejamos de la investigación pura. No se trata de realizar muestreos que supongan amplia dedicación de tiempo a la recolección de datos o cuestionarios amplísimos; basta con un número suficiente de usuarios elegidos de forma correcta y unas pocas preguntas estratégicas. Deben convertirse en una herramienta de utilidad para el conjunto de la organización (políticos, gerentes, responsables, trabajadores, etc.).

- Economía, brevedad y comprensibilidad: no hay entrevistadores propiamente dichos, ya que la modalidad de encuesta es del tipo autoadministrada. Con el fin de que el cuestionario se pueda rellenar rápidamente, se establecen pocas preguntas, precisas y claras, con un formato que facilita su cumplimentación (usualmente, dos folios en forma de cuadernillo). Los usuarios deben entender y aceptar el cuestionario, de modo que éste se redacta incluyendo explicaciones y precisiones en cada item que mide una dimensión de la calidad.

- Funcionalidad analítica: la encuesta debe proporcionarnos tres niveles de análisis. El primero, centrado en el servicio municipal concreto que se considere, segmentando a los usuarios en función de variables relevantes (turno de uso, modalidad de uso, tipo de prestación, etc.); el segundo aportando unos resultados comparables entre diversos servicios del Ayuntamiento del mismo carácter (Bibliotecas, Universidad Popular, Escuela de Música y Danza, etc.); por último, debe permitir la comparación entre servicios de carácter diferente (socioculturales, deportivos, de salud e integración social, etc.), para realizar contrastes entre los distintos departamentos de la organización municipal y, al mismo tiempo, poder observar la imagen global de la calidad de los servicios municipales en cada momento.

\subsubsection{Diseño de la encuesta}

Abordaremos la explicación de la metodología de las Encuestas de Satisfacción de Usuarios (ESU) por el flanco más débil, el de las limitaciones. Es importante que todos los interesados en estudios sobre percepción ciudadana se aproximen de la forma más práctica posible a la finalidad de la información obtenida y a los objetivos concretos que se quieren alcanzar. 
Como todo instrumento que nace con muchos requerimientos y con recursos escasos, la encuesta ha tenido que acotarse notablemente. Para un cuestionario que rellena directamente el encuestado, la facilidad de cumplimentación ha de ser su atributo fundamental, lo cual tiene importantes consecuencias prácticas: la fundamental es que hay que renunciar a información que podría ser muy valiosa en favor de unos pocos objetivos informativos realmente útiles. Así, hubo que descartar la medición de la «expectativa» del usuario en cada uno de los indicadores de calidad, ya que complicaba y alargaba el tiempo de respuesta con la consiguiente repercusión negativa en la actitud de colaboración del usuario.

No obstante, la información resultante de la aplicación del cuestionario a un servicio específico se ha complementado con otra de tipo cualitativo, que nos refleja los matices, la variabilidad de las percepciones. El análisis de las reclamaciones y sugerencias y muy especialmente los grupos de discusión y las entrevistas en profundidad de los cualitativos que se aplican conjuntamente con las ESU, nos perfilan considerablemente las fuentes de satisfacción e insatisfacción del usuario y nos ayudan a interpretar los resultados de la encuesta, tal como veremos más adelante. Las preguntas abiertas (una o dos a lo sumo) que suelen incluirse en el propio cuestionario responden al mismo fin y tienen la misma utilidad.

Las fases de la aplicación de la ESU son las que a continuación se describen:

- Establecimiento de la relación entre el coordinador del Servicio estudiado y los técnicos responsables de las encuestas de satisfacción de usuarios. El cuestionario estándar que se aplica a los Servicios Socioculturales municipales se centra en el servicio específico que se pretende medir y, por tanto, es necesario clarificar a los responsables del servicio la naturaleza de tal análisis. Esto implica que se debe detallar al máximo qué indicadores se van a manejar, qué se pretende conseguir e, incluso, las posibles intervenciones que se puedan derivar de dicho análisis (Peiró, Martinez-Tur y Ramos, 1999). Se trata de hacer comprender a los responsables de los servicios que la satisfacción de los usuarios respecto de la atención recibida debe ser concebida como una medida de control de calidad, por lo que su estudio y valoración es importante para la gestión y el trabajo de los profesionales de los servicios municipales, con la perspectiva de conseguir una mejor adaptación a las necesidades y deseos de los ciudadanos. En definitiva, se pretende conseguir que no se enfoquen las medidas de la calidad como una «inspección» del servicio y de los trabajadores del mismo, como una suerte de fiscalización, lo cual crearía muchas resistencias. La cuestión no deja de ser importante si se tiene en cuenta que buena parte de las medidas correctoras que se tengan que aplicar dependen de los mismos profesionales, de manera que la orientación que se persigue es de carácter participativo. En este sentido, los responsables de cada servicio facilitan los segmentos de usuarios que son relevantes para poder encuestar o entrevistar a un grupo significativo de cada uno de ellos, así como otros aspectos básicos para que funcione el circuito operativo de la aplicación del cuestionario: quién se lo va a entregar al usuario, en qué momento, dónde lo va a rellenar, dónde lo va a depositar, cómo se va a hacer llegar al departamento responsable del informe, tiempos de realización, etc.

- Una vez establecida la relación entre el equipo de investigación y el responsable del servicio, se definen varios aspectos que afectan al modelo estándar de cuestionario:

- Se especifica cada uno de los atributos de calidad concretándolos para el servicio estudiado; en algunos casos se amplía el número de indicadores que hacen relación a un atributo, en otros se modifica el sentido.

- Los responsables de los servicios eventualmente identifican otras dimensiones de calidad que a ellos les ayudarían a mejorar la prestación del servicio y que quieren someter a valoración.

- También se contemplan otra serie de cuestiones que al servicio implicado le sirven para hacer su programación, planificar o simplemente saber cómo actuar en determinadas situaciones. En definitiva, se trata de obtener información útil para adaptarse mejor a las necesidades del usuario.

- Normalmente, una o varias personas del servicio estudiado (las que se determinen para mayor operatividad del proceso) son las que facilitan al usuario el cuestionario en el momento que se haya establecido (a la entrada o salida, después de la prestación) para que él/ella mismo/a lo rellene (si puede ser en el momento) y le indica dónde puede cumplimentarlo (lugar establecido al objeto) y depositarlo una vez rellenado (en una urna, en un mostrador). Con frecuencia, los responsables elegidos para entregar el cuestionario al usuario le explican el interés que tiene el Ayuntamiento y el servicio concreto que está utilizando por conocer su opinión y así poder mejorarlo. En algunos casos, es el propio usuario quien toma el cuestionario de un lugar determinado, lo cumplimenta y lo deposita en el receptáculo dispuesto a tal efecto.

\subsubsection{Diseño del cuestionario}

El cuestionario estándar mide el estado de los atributos determinantes de la calidad señalados más arriba, pero adaptados por los técnicos de investigación y evaluación a los servicios socioculturales específicos. Se evalúan tres grandes dimensiones presentes en todos los servicios, instalaciones, profesionales y trámites administrativos, y otro conjunto de dimensiones específicas de cada servicio si ello es preciso. 


\section{Instalaciones:}

- En todos los servicios municipales se hace una pregunta global dicotómica (sí/no) acerca de la instalación: se trata de valorar la adecuación o no de la instalación a la actividad que se realiza en ella (música, pintura, lectura, etc.).

- Valoración de los aspectos físicos y de seguridad del edificio donde se desarrolla la actividad:

- Limpieza (en el interior de la instalación).

- Accesibilidad (si resulta fácil localizar las diferentes dependencias).

- Estado de conservación (si el edificio está deteriorado y/o cuenta con un buen mantenimiento, etc.).

- Seguridad (en las aulas, en las dependencias municipales).

- Eventualmente, también se incorporan en esta parte del cuestionario otros aspectos de la calidad relativos a elementos tangibles pero debidamente adaptados al tipo de servicio de que se trate. Por ejemplo, en las ESU's que se aplicaron en la Escuela Municipal de Música y Danza y en las Bibliotecas Municipales se incluyeron otros aspectos relevantes para estos servicios, como los siguientes:

- Climatización (temperatura ambiente).

- Ambiente (sonido, luminosidad, ruidos, permite concentrarse, etc.).

- Confort (comodidad de los asientos/espacio para moverse, espacio disponible para leer/estudiar, para la práctica instrumental, etc.).

Estos aspectos relativos a cuestiones ambientales en la actualidad se han incorporado de forma estándar al cuestionario de las ESU's que miden la calidad en servicios en los que el equipamiento es parte fundamental de la prestación.

Profesionales:

Se refiere a las personas que entran en contacto con el usuario en el nivel más cualificado de la prestación (profesores, educadores, psicólogos, trabajadores sociales, etc.); se mide tanto su competencia técnica como su capacidad de relación interpersonal. Los indicadores de calidad seleccionados para todos los servicios son:

- Simpatía, amabilidad.

- Profesionalidad, competencia (si ejerce su función satisfactoriamente).

- Motivación, comprensión (buena predisposición).

- Comunicación (utilizan un lenguaje claro y sencillo, conectan con el usuario).

- Dedicación (al alumno/a, al trabajo).

Nuevamente, para obtener la máxima información sobre cada uno de estos atributos en función del servicio que se presta, pueden añadirse al cuestionario otros aspectos, tales como res- peto, honestidad, confidencialidad, etc. Así, por ejemplo, en la ESU llevada a cabo en las Escuelas Infantiles, se desdobló el atributo de calidad «comunicación» en dos sentidos importantes para comprender la percepción de la calidad que experimentan los padres al utilizar este servicio:

- Comunicación con los niños/as (conecta bien con los niños/as).

- Comunicación con los padres (conecta bien con los padres).

\section{Trámites administrativos:}

La cuestión de los trámites administrativos ha sido tradicionalmente la faceta menos agradable para el usuario, siempre previa a la utilización de los servicios públicos. Los aspectos que se someten a valoración son los siguientes:

- Horarios de atención al público.

- Agilidad en la gestión de los trámites administrativos (rapidez en la gestión y tramitación de los asuntos).

- Desplazamiento realizado (hasta el lugar donde se realizan los trámites de inscripción).

- Amabilidad del personal (personal que gestiona la tramitación).

Los requisitos administrativos necesarios para utilizar los servicios municipales varían según el caso, por lo cual ha habido que incluir en ciertas ocasiones otra serie de subdimensiones diferenciadas para cada uno de ellos. Así, en la ESU realizada en el Departamento de Usuarios se valoró:

- Servicio de información (por teléfono/en persona, le han ayudado, ha sido clara y correcta, etc.).

- Sistema de números (coger número para ser atendido).

- Finalmente, el cuestionario incluye, como hemos apuntado, una pregunta abierta, válida para todos los servicios municipales, acerca de cómo mejorar el funcionamiento general del servicio según el parecer del usuario. En este espacio, los usuarios plasman sus quejas, observaciones y sugerencias libremente, aunque más tarde el sociólogo encargado del análisis de la ESU procura sintetizarlas a efectos informativos.

Dimensiones de calidad identificadas por el equipo responsable del servicio a evaluar:

Como hemos señalado más arriba, en las reuniones preparatorias de la ESU con el coordinador y/o con el equipo de trabajo del servicio a estudiar con frecuencia se determinan otras dimensiones singulares a añadir a las genéricas que se miden en todos los servicios. Ejemplos de tal especificación de las dimensiones de la calidad serían los siguientes:

- En la Escuela Municipal de Música y Danza se contemplaron aspectos relativos a los cursos que se imparten: horarios, dotación de las aulas, préstamo de instrumentos, variedad de la oferta, precios y duración de las clases. 
- En las Escuelas Infantiles se valoraron: Equipo de Atención Temprana (psicólogo, logopeda, etc.), reuniones trimestrales padres-educadores, entrevistas individuales padres-educadores, actividades extraescolares y calendario escolar.

- En las ESU realizadas en las dos Bibliotecas Municipales: horarios de apertura, dotación de fondos, especialización de fondos, actualización de fondos, plazas (asientos), duración del préstamo, sistema de penalizaciones, medios técnicos (desarrollo informático) y publicaciones periódicas.

Lógicamente, y en línea con la política de mejora continua que es el eje de la filosofía de calidad de la Institución, en cada nuevo servicio que se analiza se perfecciona el modelo de cuestionario con el fin de acercarnos mejor a la percepción del usuario. En consecuencia, en los últimos estudios se han incluido tres nuevas cuestiones:

- Valoración global del servicio.

- Atención y/o cobertura de las necesidades o problemática del usuario y, cuando proceda, las razones de insatisfacción.

- Valoración de la política que el Ayuntamiento estállevando a cabo en las diversas áreas (infancia, educación, salud, etc.), a través de una serie de actuaciones en esa materia.

\subsubsection{Variables}

Se parte de un conjunto de variables sociodemográficas que nos permiten conocer algunas características del usuario de los servicios municipales: sexo, edad, nivel educativo y actividad. Dadas las limitaciones que se han establecido a priori en la elaboración del cuestionario, hay variables de tipo socioeconómico (ingresos, ocupación, etc.), que, aunque sería interesante conocer, se han omitido con el fin de incluir otras de clasificación más útiles para el servicio analizado. Así, se introducen otras variables que sólo afectan al servicio concreto que se va a estudiar y que contribuyen a discriminar las diferentes opiniones acerca de la prestación. Por citar algunos ejemplos: en las ESU's de la Escuela Municipal de Música y Danza y de la Universidad Popular era relevante saber la «actividad», el «curso» y el «nivel» del usuario. En las Escuelas Infantiles, la «nacionalidad de los padres» y el «horario» al que se acogían (normal o ampliado); en las Bibliotecas Municipales, el «uso que se le da habitualmente a la biblioteca» (estudio y lectura, préstamo de libros, ambas cosas) y el «horario» en que se utiliza habitualmente (mañana o tarde). En definitiva, se trata de obtener información complementaria útil para el control de calidad, desagregando la opinión que tienen los usuarios sobre las dimensiones de calidad predeterminadas según variables de clasificación, que pueden ser la causa de una valoración determinada, presente o futura.

\subsubsection{Escalas de medida}

Para la medición de la valoración global del servicio y la satisfacción de los usuarios en relación a los atributos de calidad estandarizados se utiliza una escala tipo Likert, mediante la cual a la persona que rellena el cuestionario se le pide que valore el servicio que está utilizando desde 0 («muy insatisfecho») hasta 10 («completamente satisfecho»). La idea básica es que en una escala de satisfacción del 0 al 10 , cualquier puntuación por debajo de «10» significa un motivo de insatisfacción, la señal de una deficiencia.

En algunos casos, para los aspectos sometidos a valoración a petición del equipo responsable del servicio específico, que no forman parte de los indicadores estándar, se aplica una escala ordinal, que va desde «muy bien», en el mejor de los casos, a «muy mal», en el peor.

En cuanto a las cuestiones incluidas con el fin de facilitar la programación y actuación de los responsables del servicio cuya calidad se va a medir, se establecen preguntas cerradas con respuestas prefijadas por ellos mismos.

Por último, las observaciones, quejas y sugerencias de los entrevistados, para las cuales se deja un espacio abierto, se codifican en unas pocas categorías, según las tendencias opináticas más intensas, para facilitar su análisis.

\subsubsection{Informe}

La investigación que es la ESU culmina con un informe detallado de resultados, presentado, junto con el informe del estudio cualitativo correspondiente, a la dirección técnica y/o gerencia, al responsable político del área y a los equipos de trabajo de cada servicio estudiado. Para mayor claridad del informe, el análisis e interpretación de datos viene expresado simplemente en forma de frecuencias, proporciones y medias, acompañadas de algunos gráficos, al objeto de que en todos los niveles del Ayuntamiento y de los Patronatos el personal pueda comprender rápidamente qué información se obtiene, qué conclusiones se derivan de la misma y las recomendaciones que se hacen; sólo eventualmente se presentan análisis estadísticos más sofisticados (análisis multivariantes, como factoriales o discriminantes). Se pretende así contribuir a que todos los equipos de trabajo implicados puedan valorar y utilizar las conclusiones, que se desarrollen visiones compartidas de la situación y se formulen líneas de actuación orientadas por el fin de mejorar la calidad del servicio. La información que se proporciona a cada equipo de trabajo participante es la relativa a su propio servicio, pero también se difunde al resto de la Institución. El objetivo final es que todos los servicios del Ayuntamiento y todas las audiencias interesadas 
Figura 7

\section{PERCEPCIÓN DE LOS USUARIOS DE LA ESCUELA MUNICIPAL DE MÚSICA Y DANZA DE LOS ATRIBUTOS DE CALIDAD (Escala de 0 a 10)}

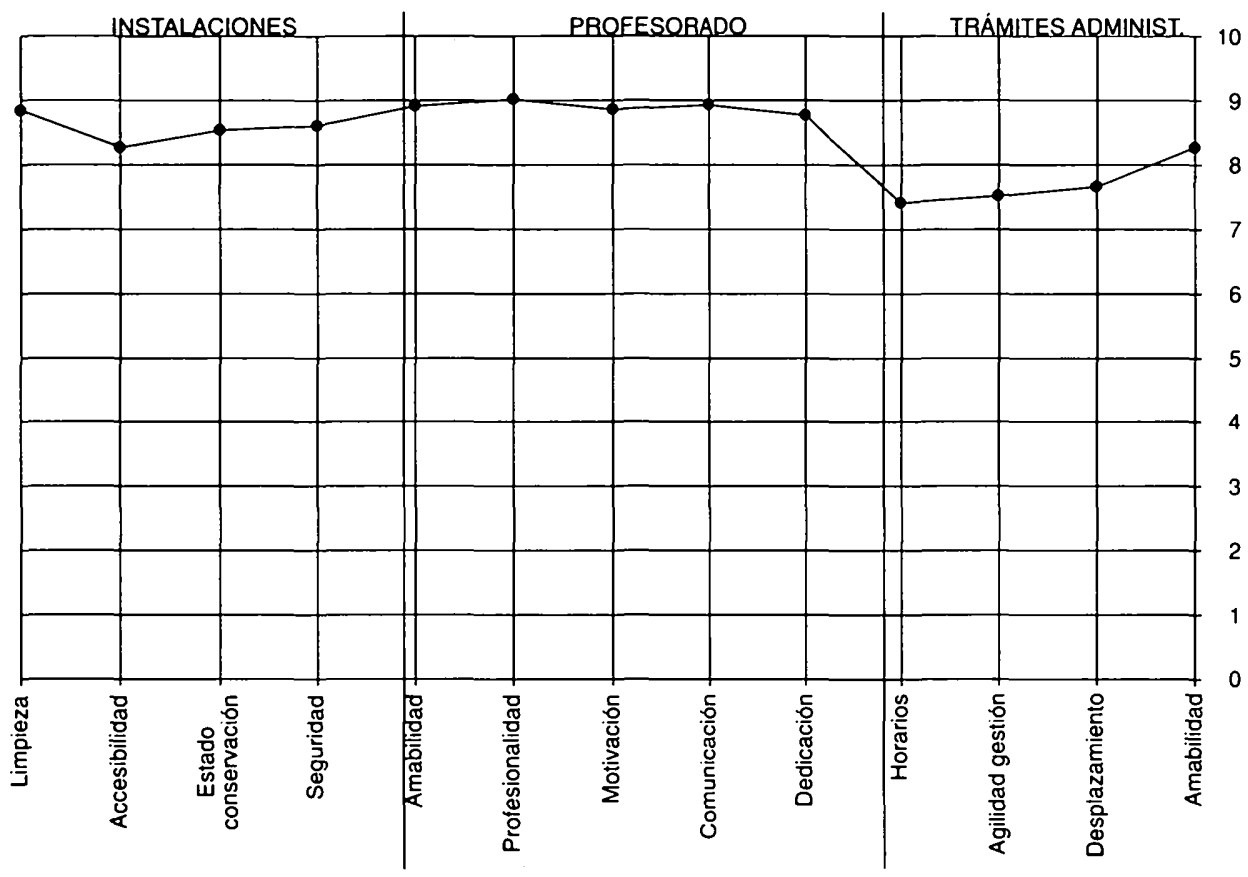

Fuente: Dirección de Investigación Social y Evaluación. Encuesta de calidad de la Escuela municipal de müsica y dama, 1998.

accedan a la información y asimismo que se promueva la planificación con la participación de los ciudadanos y la estimulación de los empleados públicos en el desarrollo estratégico de la organización.

\subsubsection{Evaluación continua}

La utilización de los resultados debe servir para iniciar un proceso de mejoras en los servicios según los resultados obtenidos en los estudios de calidad. Cada cuatro años se vuelve a evaluar el mismo servicio con el fin de controlar si se han llevado a cabo las acciones correctoras sugeridas por el informe, asegurando así la consecución de un mayor nivel de calidad y evitando el retroceso en el mismo. Nuevamente, serán los usuarios los que permitan medir el estado de los atributos de calidad presentes en la prestación de los diferentes servicios municipales y los que evalúen si con la implementación de medidas correctoras el servicio se adapta mejor a sus necesidades y deseos.

\begin{tabular}{|lccc|}
\hline \multicolumn{5}{c|}{ Figura 8} \\
\multicolumn{5}{c|}{ Puntuaciones medias de los indicadores de calidad } \\
en algunos servicios socioculturales (escala 0.10$)$
\end{tabular}

Fuente: Dirección de Investigación Social y Evaluación. 


\subsection{Aproximación metodológica 2: Los estudios cualitativos en la medición de la satisfacción de usuarios}

Al lado de las encuestas de calidad, el Departamento de Investigación Social y Evaluación de Políticas Municipales del Ayuntamiento de Alcobendas realiza para cada Servicio Sociocultural evaluado un estudio cualitativo, utilizando las más comunes técnicas cualitativas de investigación social. En virtud de la naturaleza y características del servicio considerado y de la población que éste atiende, se emplean unas u otras técnicas, predominando la entrevista en profundidad y el grupo de discusión, eventualmente en combinación porque así lo aconseje la situación y/o para optimizar la potencia informativa del diseño de la investigación. Es práctica habitual que las dos prospecciones, la cuantitativa y la cualitativa, coincidan cronológicamente en su aplicación, con objeto de evitar los inconvenientes metodológicos derivados de la recogida de datos en momentos distintos y de no afectar más de lo indispensable la dinámica normal de los equipos de trabajo y de los usuarios.

Los estudios cualitativos en la medición de la satisfacción de los usuarios comprenden las fases habituales que comporta la utilización de este tipo de técnicas, pero convenientemente adaptadas a la especificidad del objeto de estudio, de tal modo que las investigaciones realizadas sirvan por encima de todo a las necesidades informativas de la Institución. No nos extenderemos aquí, por consiguiente, en el relato de la aplicación de unas técnicas sobradamente conocidas entre los sociólogos, pero sí conviene dar noticia de aquellos extremos que son resultado de una adaptación metodológica y poseen alguna singularidad.

- En la primera fase de la investigación cualitativa, se conciertan varias entrevistas con distintos técnicos y auxiliares del servicio evaluado que tengan contacto directo con los usuarios, con el fin de que contribuyan a establecer los ejes temáticos fundamentales del guión de las entrevistas en profundidad y/o los grupos de discusión, incorporando la propia percepción del personal del servicio sobre las fortalezas y debilidades del mismo desde la perspectiva del usuario (el número de estas entrevistas preparatorias al personal del servicio es variable, dependiendo de las características del mismo, pero normalmente no supera la cifra de cuatro). Aunque existe un guión-tipo de preguntas o temas de discusión para todos los servicios estudiados, es práctica habitual que se incluyan otras cuestiones en función de las características específicas de cada servicio y de los intereses evaluativos del personal del mismo, del mismo modo que se hacía en las ESU's.

- En la fase de diseño de la muestra estructural del cualitativo, se selecciona a los usuarios aleatoriamente a partir de los listados nominales que suelen poseer los servicios y en virtud de las tipologías básicas que ofrecen los mismos (por sexo, edad, tipo de uso del servicio, etc.); cuando estos listados no existen (en el caso del Auditorio Municipal, por ejemplo, una media de más del $70 \%$ de los asistentes a un espectáculo no está registrado en listado alguno), se seleccionan los usuarios directa y personalmente, procurando el azar, en los propios equipamientos de los servicios evaluados.

- Cuando el investigador contacta con los usuarios seleccionados (o con los sustitutos que se han escogido del mismo modo), procura citarlos, siempre que sea posible, en una dependencia municipal distinta de la del servicio evaluado, para eliminar esta fuente de contaminación de su discurso, pero en algunos casos se han realizado entrevistas en los propios domicilios de los usuarios en aras de facilitarles al máximo su participación en el estudio. Con la misma filosofía, siempre se adapta el horario de las entrevistas o de los grupos a la conveniencia de los usuarios que participan en el estudio.

- En las sesiones de los grupos de discusión suele invitarse a un refrigerio o a un café a los participantes, para favorecer el ambiente coloquial, pero en ningún caso se ofrece a los usuarios recompensa alguna por su asistencia más allá de la intangible que comporta su colaboración en la mejora de los servicios que se les prestan. La excepción la constituyen los grupos de discusión formados con niños (estudios de calidad de las Bibliotecas Municipales o del Auditorio Municipal, por ejemplo), en los que se obsequia a los pequeños con literatura infantil.

Los textos producidos como resultado de la transcripción de las cintas magnetofónicas en las que se han grabado las entrevistas o las discusiones de los grupos se someten a un análisis de contenido de tipo semántico, en sus dos vertientes clásicas: análisis temático y análisis de la evaluación de Osgood (también conocido como de aserciones evaluativas), modalidades elegidas frente a otras posibles, como serían los análisis a nivel sintáctico o a nivel pragmático (NavarRo y Díaz, 1994: 196-208), menos apropiados aquí para los objetivos institucionales de medición de la calidad de los servicios. El discurso de los usuarios entrevistados o participantes en los grupos de discusión se analiza, por tanto, desde el punto de vista de los temas capitales emergentes y desde el punto de vista de las valoraciones sobre los principales aspectos involucrados en la prestación del servicio. Sin perjuicio de que los usuarios proyecten en su discurso otras cuestiones de su interés, los ejes temáticos sobre los que se les interpela son habitualmente los siguientes:

a) Necesidades a las que responde el servicio (funciones del mismo) desde la perspectiva de sus usuarios, poniendo de relieve el posible contraste existente entre las funciones formales determinadas por la Institución y las que aquéllos le atribuyen.

b) Demandas de sus usuarios (instalaciones, dotaciones del equipamiento, recursos para la prestación del servicio, sistemas organizativos, personal, información y difusión, actividades complementarias...), que se resumen en un listado al final del 
apartado correspondiente en el informe definitivo del cualitativo.

c) Sensibilidad social e institucional (de la sociedad, de la Administración, del Ayuntamiento) en relación con la problemática a la que atiende el servicio, recabando la percepción del entorno social y de la acción de la Administración en general y de la Institución en particular respecto de los problemas y necesidades de los usuarios.

El análisis de discurso contempla todos estos ejes independientemente del orden en que los usuarios aborden los mismos y el sociólogo que realiza la investigación se sirve, para analizar e interpretar la información recogida, de una rejilla temática (Figura 9) que, aunque no registra cantidad sino intensidad, contribuye a poner de manifiesto cuáles son los temas que más interés suscitan y qué valoración reciben.

Del análisis cualitativo de los discursos de los usuarios se desprende que existen unos aspectos del servicio que se ajustan muy de cerca a las expectativas y demandas de aquéllos, mientras que hay otros aspectos que se valoran como manifiestamente mejorables: se perfilan, en definitiva, fortalezas y debilidades de los servicios sometidos a estudio, que son las cuestiones que en última instancia interesan a la Institución en su filosofía de calidad de la gestión. Las fortalezas y debilidades de los Servicios Socioculturales evaluados se plasman, a título de síntesis, en un diagrama de intensidad (Figura 10) que permite visualizar con claridad y rapidez las conclusiones principales del cualitativo en lo que se refiere a la medición de la satisfacción de los usuarios de esos servicios, de tal modo que los aspectos que figuran en la parte superior del diagrama son los mejor valorados, los que generan mayor satisfacción en los usuarios, mientras que los aspectos que aparecen en la parte inferior del diagrama son los peor valorados, los que producen menos satisfacción en los usuarios y los que, consecuentemente, hay que mejorar para aumentar la calidad del servicio percibida por el usuario.

Los informes de las investigaciones cualitativas sobre la calidad de los Servicios Socioculturales de Alcobendas se redactan siguiendo el orden señalado para los ejes temáticos sobre los que se lleva a cabo el análisis de contenido de discursos, y en ellos se incluye una selección de fragmentos de texto transcrito que resultan especialmente significativos, de tal manera que ilustren, por así decir, la lectura del informe con la propia palabra del usuario. Con objeto de sintetizar la información del cualitativo, adecuando el documento a los usos administrativos propios de la Institución, entorno en el que es frecuente la escasez de tiempo para detenerse en textos densos y extensos, el informe dispone un capítulo-resumen donde se extractan sumariamente las principales conclusiones de la investigación cualitativa. Con este informe, que se añade al informe de la ESU correspondiente, se cierra el cualitativo y el estudio de calidad del servicio hasta el momento evaluativo siguiente, nor-

\section{Figura 9}

Ejemplo de rejilla temática para anälisis de discursos Grupos de Discusión de las Escuelas Infantiles Municipales

\begin{tabular}{|c|c|c|c|}
\hline & \multicolumn{3}{|c|}{ Registros } \\
\hline Temas y subtemas & Grupo 1 & Grupo 2 & Grupo 3 \\
\hline \multicolumn{4}{|l|}{ Funciones } \\
\hline Custodia & $\begin{array}{l}++H+++ \\
H+H\end{array}$ & $\begin{array}{l}+H+H+t \\
++H .\end{array}$ & $+H++H$ \\
\hline Educación & $H+t+t+$ & $\begin{array}{l}+H+\ldots+. \\
+\end{array}$ & $\begin{array}{l}+++H+H \\
H .+\end{array}$ \\
\hline Socialización & $\begin{array}{l}. H+H+H \\
+H+\end{array}$ & $\begin{array}{l}+.+t+t+ \\
+t\end{array}$ & $\begin{array}{l}+H+H+H \\
H+\end{array}$ \\
\hline
\end{tabular}

\begin{tabular}{|c|c|c|}
\hline Instalaciones & & \\
\hline Edificio & $\ldots+\ldots \ldots \ldots$ & $\ldots \ldots \ldots \ldots$ \\
\hline Mobiliario, dotaciones &..$+++++\ldots$ & $\ldots . . .+t+$ \\
\hline
\end{tabular}

\begin{tabular}{|c|c|c|c|}
\hline & $\theta$ & $\cdot \ldots$ & - \\
\hline Proyecto educat. & $+\ldots \ldots++\ldots$ & $\cdots \ldots$ & $.+t+$ \\
\hline Seguridad & ......t+ & $+t+\ldots \ldots+$ & $+\cdots \cdot \ldots .+$ \\
\hline Organización & $\ldots+H+$ & $++H \cdot \ldots$ &..+ \\
\hline \multicolumn{4}{|l|}{ Horarios } \\
\hline $\begin{array}{l}\text { Diario } \\
\text { Vacaciones }\end{array}$ & $\begin{array}{l}\ldots+\ldots+. . \\
\ldots+\ldots \ldots\end{array}$ & $\begin{array}{c}+\ldots \cdots \\
\cdots \cdots\end{array}$ & H... \\
\hline Alimentación & $\begin{array}{l}+H+H++H \\
H+\end{array}$ & $\begin{array}{l}+H++H \\
++\end{array}$ & $\begin{array}{l}++H+t+ \\
+t\end{array}$ \\
\hline Atención médica & $\ldots+\ldots++$ & $++\ldots+\ldots$ &.++++ \\
\hline \multicolumn{4}{|l|}{ Personal } \\
\hline Profesorado & $\begin{array}{l}+H+H++ \\
+H .\end{array}$ & $++++t$ & $\begin{array}{l}+H+. . H \\
H+\end{array}$ \\
\hline Auxiliar & $+H \ldots$ & $\begin{array}{l}++H \cdot+\ldots \\
+t\end{array}$ & $t+t+$ \\
\hline Externo & . H+ & $+\cdot \ldots+$ & $+t+H$ \\
\hline Participación & ……+. & $\cdots++\cdots$ & $\ldots+++\ldots$. \\
\hline Información & $\cdots$. &..$++\ldots$ & $\cdots++\cdot .+$ \\
\hline
\end{tabular}

Simbologia: + Adhesión.

+ Aceptación.

. Descripción, neutro.

- Negación.

Rechazo.

malmente cuatro años más tarde, siguiendo el carácter longitudinal que se ha dado a estas investigaciones.

\section{A modo de conclusión}

La metodología para la medida de la calidad de los servicios municipales que se aplica en el Ayuntamiento de Alcobendas es consecuencia de la conjunción pragmática de varios factores. 


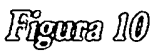

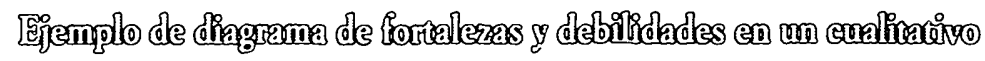

\section{PRINCIPALES FORTALEZAS Y DEBILIDADES DE LA UNIVERSIDAD POPULAR}

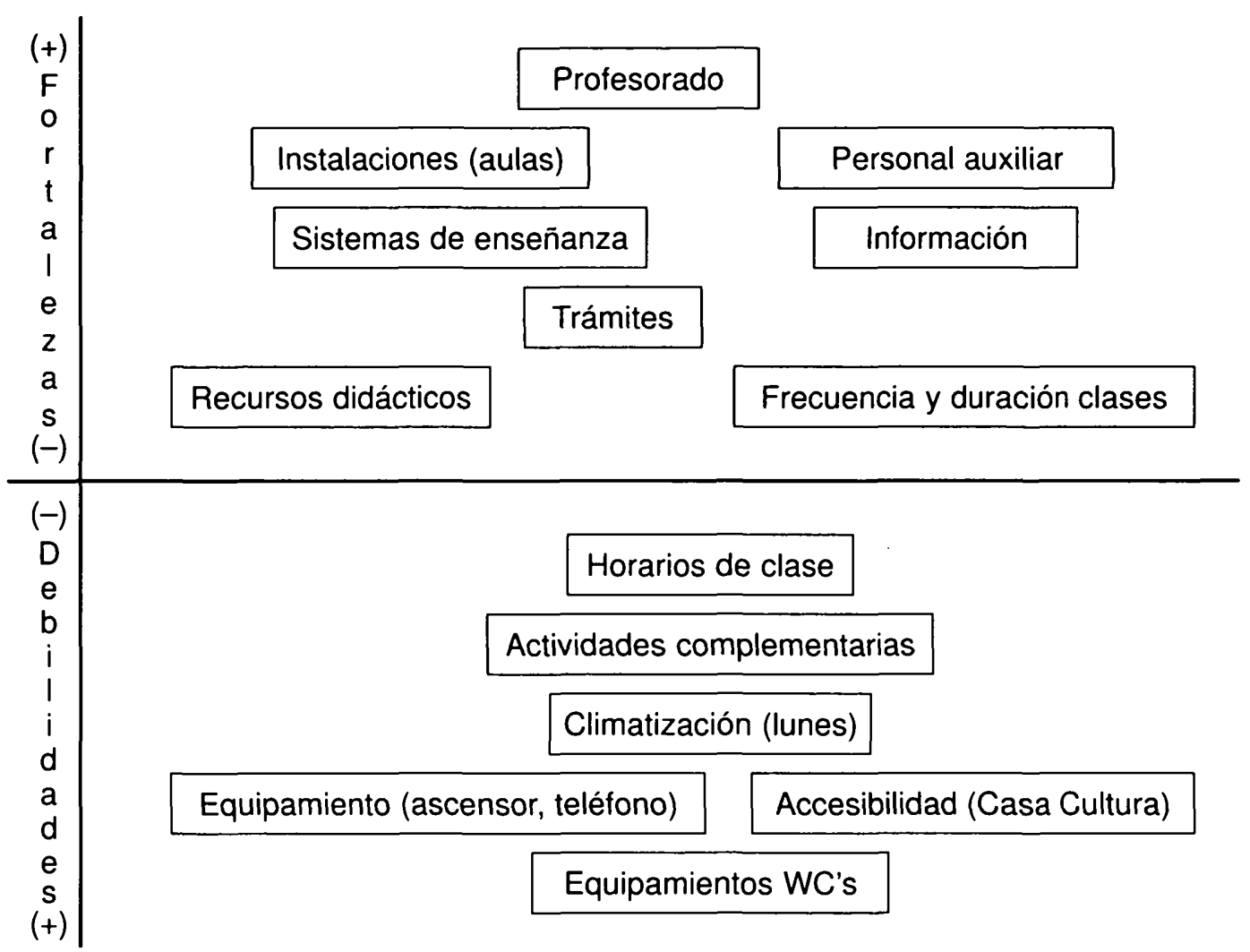

En primer lugar, parte de una lectura adaptada a la Administración local de los principios de gestión de la calidad en empresas de servicios según el modelo EFQM, que concede una especial relevancia a la satisfacción de los clientes. Igualmente, el elenco de indicadores empleados para medir la calidad de los servicios municipales en general y de los Servicios Socioculturales en particular está inspirado en el conjunto de indicadores de la escala Servqual para el control de la calidad en empresas de servicios, convenientemente adaptada a las necesidades informativas de la Institución. Los instrumentos de medida utilizados para el control de la calidad en estos servicios son las más conocidas técnicas cualitativas y cuantitativas de investigación social al uso, pero también amoldadas a este objeto de estudio y a las circunstancias empíricas en las que tienen lugar las investigaciones. El resultado es un modelo propio de evaluación de servicios públicos, flexible y relativamente fácil de aplicar, que permite descubrir los puntos débiles de los servicios, diseñar mejoras en los mismos y controlar los efectos de las mejoras a lo largo del tiempo. Con este dispositivo no se trata necesariamente de eliminar todos los aspectos del servicio que han resultado insatisfactorios para el usuario, sino de mejorar especialmente aquellos que, debidamente seleccionados y valorados por la organización (dependiendo de la disponibilidad de recursos y de la gravedad de los problemas detectados), estén más alejados de los deseos de los usuarios. Ésta es la esencia del Sistema de Calidad del Ayuntamiento de Alcobendas y la circunstancia que da buena parte de su funcionalidad a su Departamento de Investigación Social y Evaluación de Políticas Municipales. Creemos que el desarrollo de este modelo de medición de la calidad en los servicios públicos locales supone un modesto paso adelante en el camino de dar utilidad práctica a la Sociología, exigencia cada vez más intensa en todos los ámbitos de la empresa y la Administración. Es evidente que la gestión de la calidad en los servicios a las personas precisa de un particular enfoque de carácter científico-social para la organización de las prestaciones y de un modelo de control que proporcione una solución práctica a las particulares necesidades informativas que la gestión de la calidad en estos campos exige: pensamos que el modelo y la metodología arriba expuestos ofrecen una referencia teórica y una respuesta empírica que satisface en alguna medida esos requerimientos. 
* Dirección de Investigación Social y Evaluación de Políticas Municipales del Ayuntamiento de Alcobendas (Madrid).

${ }^{1}$ Alcobendas es una ciudad situada en el norte de la corona metropolitana de Madrid, en el punto kilométrico 16 de la N-1. Su término municipal ocupa una superficie de $45 \mathrm{~km}^{2}$. Predominan las actividades industriales y de servicios. Su población alcanza las 91.373 personas al 1 de enero de 2000 y su renta familiar disponible supera en un $13 \%$ a la media de la Comunidad Autónoma (1995)

\section{Bibliografía}

Ayuntamiento de Alcobendas (1997), Calidad y modemización en la gestión puiblica, Barcelona: Ayuntamiento de Alcobendas-Ed. Gestión 2000

- (1998), "Cartas de Servicio», Semana Europea de la Calidad. 1. Encuentro de Iniciativas de Mejora, Madrid: Ayuntamiento de Alcobendas.

Ayuntamiento de Santurtzi (1998), Retos sociológicos y organizativos. Propuestas de mejora en el Ayuntamiento de Santurtzi, Bilbao: Ayuntamiento de Santurtzi.

BazAGA, I., et al. (1998), El consumo y la calidad de los servicios públicos. Estudio de caso de la ciudad de Coslada, Madrid: Consejeria de Medio Ambiente y Desarrollo y Ayuntamiento de Coslada.

Brown, A. (1992), Gestión de la atención al cliente, Madrid: Díaz de Santos.

Club Gestión de Caldoad (1999), Modelo EFQM de Excelencia, Club de Gestión de Calidad y European Foundation for Quality Management, Madrid.

CHiAs, J. (1991), El mercado son personas: el marketing en las empresas de servicios, Madrid: McGraw-Hill.

Díz, A. (1992), Gestión sociocultural. La eficacia social, Madrid: Comunidad Autónoma de Madrid.

Dirección General de Calidad de los Servicios (1999), Satisfacción de los ciudadanos y ciudadanas en la Comunidad de Madrid, Madrid: Consejería de Hacienda de la Comunidad de Madrid.

DRUCKER, P. (1985), «¿Qué resultados puede esperar? Una guia para el usuario de la Dirección por objetivos», Barcelona: DC 2.033. IESE.

Drudis, A. (1992), Planificación, organización y gestión de proyectos, Barcelona: Gestión 2000.

Federación de Municipios de Madrid (1997), Curso sobre gestión de calidad en los servicios públicos, Madrid.

FLIPO, J. P. (1989), Gestión de empresas de servicios, Barcelona: Gestión 2000

Grande Esteban, I. (1996), Marketing de los servicios, Madrid: ESIC.

Grupo de Trabajo de Adaptación de Normas de Calidad de la Sección de Calu. dad en las Administraciones Públucas (1997), Guia para la gestión de calidad de los servicios públicos (Adaptación de la norma ISO 90042), Madrid: Asociación Española para la Calidad.

HaYEs, B. E. (1995), Cómo medir la satisfacción del cliente, Barcelona: Gestión 2000.

IVAP (1995), Gestión de la calidad en la Administración Pública, Barcelona: IVAP y Gestión 2000

MC CONKEY, D. D. (1972), «Veinte formas de eliminar la Dirección por objetivos», Management Review, traducción de J. L. Samaranch, ESADE, 1982.

Ministerio de Administraciones PÚblicas (1999), Guía de autoevaluación para la Administración pública, Madrid: Ministerio de Administraciones Públicas y $\mathrm{BOE}$.

Navarro, P., y Diaz, C. (1994), «Análisis de contenido», en J. M. Delgado y J. GuthérREz (eds.), Métodos y técnicas cualitativas de investigación en Ciencias Sociales, Madrid: Síntesis: 177-224.

Peiró, J. M.; Martinez-Tur, V., y Ramos, J. (1999), «El triángulo de la calidad de servicio: una aproximación psicosocial», en Papeles del Psicólogo, núm. 74: 18-24.

Rodriguez, C. (1996), «Apuesta por la calidad», Alcobendas. Revista de Información Municipal, Madrid: Ayuntamiento de Alcobendas: 33-39.

Rosander, A. C. (1992), La búsqueda de la calidad en los servicios, Madrid: Díaz de Santos.

Segundas Jornadas sobre Medición y Mejora de los Servicios Públicos (1996), Madrid: Ministerio de Administraciones Públicas.

Shaw, J. C. (1991), Gestión de servicios, Madrid: Díaz de Santos.

Tena MLLín, J. (1991), Organización de la empresa: teoria y aplicaciones, Barcelona: Gestión 2000 .

Zetthmal, V. A.; Parasuraman, A., y Berry, L. (1993): Calidad total en la gestión de servicios. Cómo lograr el equilibrio entre las percepciones y las expectativas de los consumidores, Madrid: Díaz de Santos.

VII Congreso Nacional de la Calidad (Madrid, 16 y 17 de junio de 1998), Madrid: Asociación Española para la Calidad y Gestión 2000. 